\title{
Mechanism of Hydrofluoric Acid Formation in Ethylene Carbonate Electrolytes with Fluorine Salt Additives
}

\author{
Jonathon L. Tebbe ${ }^{\dagger}$, Thomas F. Fuerst ${ }^{\dagger}$, Charles B. Musgrave*, ${ }^{*, *}$ \\ ${ }^{\dagger}$ Department of Chemical and Biological Engineering, University of Colorado at Boulder,
} Boulder, Colorado 80309-0596

${ }^{t}$ Department of Chemistry and Biochemistry, University of Colorado at Boulder, Boulder, Colorado 80309-0215

*Address Correspondence to: email: charles.musgrave@colorado.edu

\begin{abstract}
We utilized density functional theory to examine HF generation in lithium-ion battery electrolytes from reactions between $\mathrm{H}_{2} \mathrm{O}$ and the decomposition products of three electrolyte additives: $\mathrm{LiPF}_{6}, \mathrm{LiPOF}_{4}$, and $\mathrm{LiAsF}_{6}$. Decomposition of these additives produces $\mathrm{PF}_{5}, \mathrm{AsF}_{5}$, and $\mathrm{POF}_{3}$ along with $\mathrm{LiF}$ precipitates. We found $\mathrm{PF}_{5}$ and $\mathrm{AsF}_{5} \mathrm{react}$ with $\mathrm{H}_{2} \mathrm{O}$ in two sequential steps to form two $\mathrm{HF}$ molecules and $\mathrm{POF}_{3}$ and $\mathrm{AsOF}_{3}$, respectively. $\mathrm{PF}_{5}\left(\right.$ or $\left.\mathrm{AsF}_{5}\right)$ complexes with $\mathrm{H}_{2} \mathrm{O}$ and undergoes ligand exchange to form $\mathrm{HF}$ and $\mathrm{PF}_{4} \mathrm{OH}\left(\mathrm{AsF}_{4} \mathrm{OH}\right)$ with an activation barrier of $114.2(30.5) \mathrm{kJ}$ $\mathrm{mol}^{-1}$ and reaction enthalpy of $14.6(-11.3) \mathrm{kJ} \mathrm{mol}^{-1}$. The ethylene carbonate (EC) electrolyte forms a Lewis acid-base complex with the $\mathrm{PF}_{4} \mathrm{OH}\left(\mathrm{AsF}_{4} \mathrm{OH}\right)$ product, reducing the barrier to $\mathrm{HF}$ formation. Reactions of $\mathrm{POF}_{3}$ were examined and are not characterized by complexation of $\mathrm{POF}_{3}$ with $\mathrm{H}_{2} \mathrm{O}$ or $\mathrm{EC}$, while $\mathrm{PF}_{5}$ and $\mathrm{AsF}_{5}$ complex favorably with $\mathrm{H}_{2} \mathrm{O}$ and $\mathrm{EC}$. HF formation from $\mathrm{POF}_{3}$ occurs with a reaction enthalpy of $-3.8 \mathrm{~kJ} \mathrm{~mol}^{-1}$ and a $157.7 \mathrm{~kJ} \mathrm{~mol}^{-1}$ barrier, $43.5 \mathrm{~kJ} \mathrm{~mol}^{-1}$ higher than forming $\mathrm{HF}$ from $\mathrm{PF}_{5}$. HF generation in electrolytes employing $\mathrm{LiPOF}_{4}$ should be significantly lower than those using $\mathrm{LiPF}_{6}$ or $\mathrm{LiAsF}_{6}$ and $\mathrm{LiPOF}_{4}$ should be further investigated as an alternative electrolyte additive.
\end{abstract}

Keywords: Electrolyte degradation; Hydrofluoric acid; Lithium-ion Battery; $\mathrm{LiPOF}_{4} ; \mathrm{LiPF}_{6}$ decomposition; Density Functional Theory 
1. Introduction

A major obstacle to the economical use of lithium ion batteries (LIBs) in a variety of mobile technologies, including portable electronics and especially electric vehicles is their limited service lifetimes. Commercial LIBs suffer from capacity fading - a loss in the battery's discharge capacity. Capacity fading in LIBs has been attributed to the degradation of the liquid electrolytes and lithium transition metal oxide cathodes during storage and charge/discharge cycling. Thus, understanding electrolyte degradation mechanisms is of considerable interest in the effort to reduce capacity fading and improve the performance and service lifetimes of LIBs due to the subsequent interactions of electrolyte degradation products with the solid-electrolyte interphase (SEI) in LIBs[1-6]. In this study we investigated the formation of $\mathrm{HF}$ in ethylene carbonate-based LIB electrolytes resulting from degradation of $\mathrm{PF}_{5}$, $\mathrm{POF}_{3}$, and $\mathrm{AsF}_{5}$ electrolyte additives. This $\mathrm{HF}$ formed in the electrolyte as a result these degradation reactions may react with the SEI and contribute its formation, but this is beyond our current scope.

Common liquid electrolytes in LIBs tend to be mixtures of aprotic organic solvents, such as ethylene-carbonate (EC), dimethylcarbonate (DMC), propylene carbonate (PC) and other carbonates. Because LIBs operate at temperatures below the melting point of EC (307-310K), mixtures of EC with DMC, PC, and other alkyl carbonates are used for EC-based electrolytes in LIBs to lower the mixtures' melting points and improve the stability of the electrolyte relative to redox reactions with the electrodes. These aprotic, organic liquid carbonate solvents possess large HOMO-LUMO gaps and, as a result, are stable with respect to reduction or oxidation over large voltage ranges. Consequently, these EC-based electrolytes possess large stability windows that allow them to be employed in LIBs over wide operating potentials and biases up to $\sim 5 \mathrm{~V}$, at which point they will decompose. Additionally, liquid carbonate electrolytes have ionic conductivities that are usually an order of magnitude greater than polymeric or solid-state electrolytes[6-8], which enable LIBs with these liquid electrolytes to possess higher power densities.

To achieve higher power densities and also increase the safety and service lifetimes of LIBs, lithium-salts are added to carbonate electrolytes. The desire to further improve the safety, service lifetime and power density of LIBs has motivated studies of various lithium-salt electrolyte additives[1,6,9-11]. Lithium hexafluorophosphate $\left(\mathrm{LiPF}_{6}\right)$ is comprised of a $\mathrm{Li}^{+}$ion and a $\mathrm{PF}_{6}{ }^{-}$ counter ion and is currently the dominant electrolyte salt additive in commercial LIBs with organic, EC-based electrolytes because of its ability to enhance the ionic conductivity and electrochemical stability of the electrolyte relative to other additives. Although alternative salt additives have been investigated, they either do not achieve a superior combination of conductivity and stability over $\mathrm{LiPF}_{6}[5,6,9]$ or are potentially unsafe. For example, $\mathrm{LiAsF}_{6}$ exhibits similar improvements in electrolyte conductivity and electrochemical stability relative to $\mathrm{LiPF}_{6}[1,5,6,11]$, but has not been employed in commercial LIBs due to concerns over As toxicity.

Unfortunately, $\mathrm{LiPF}_{6}$ undergoes heterolytic dissociation at elevated temperatures to form a LiF precipitate and pentafluorophosphate $\left(\mathrm{PF}_{5}\right)[2,8,9]$. Because $\mathrm{Li}^{+}$is sequestered in the $\mathrm{LiF}$ precipitate, this results in loss of working $\mathrm{Li}^{+}$. However, 
the high polarity of EC-based electrolytes separates $\mathrm{LiPF}_{6}$ as solvated $\mathrm{Li}^{+}$and $\mathrm{PF}_{6}^{-}$ions at low temperatures and thus stabilizes $\mathrm{Li}^{+}$ and $\mathrm{PF}_{6}^{-}$relative to $\mathrm{LiF}$ and $\mathrm{PF}_{5}$. This limits $\mathrm{PF}_{5}$ and $\mathrm{LiF}$ formation, and thus loss of working $\mathrm{Li}^{+}$, which improves the $\mathrm{LIB}$ lifetime[9,10,12]. However, lifetime issues still persist, especially concerning the degradation of the lithium transition metal oxide cathode, which is vulnerable to attack by hydrofluoric acid (HF) that has been proposed to form from the reaction of $\mathrm{PF}_{5}$ with $\mathrm{H}_{2} \mathrm{O}$ impurities[13]. Because lowering $\mathrm{H}_{2} \mathrm{O}$ contamination in carbonate electrolytes below the concentrations typically present in commercial LIBs (greater than 20 ppm)[14] is impractical, some reaction between this $\mathrm{H}_{2} \mathrm{O}$ and $\mathrm{PF}_{5}$ is inevitable.

$\mathrm{H}_{2} \mathrm{O}$ contamination has been suggested to drive the breakdown of $\mathrm{LiPF}_{6}$ by hydrolysis to produce $\mathrm{HF}$ by the overall reaction[2,8,9]

$\mathrm{LiPF}_{6}+\mathrm{H}_{2} \mathrm{O} \rightarrow \mathrm{LiF}+\mathrm{POF}_{3}+2 \mathrm{HF}$ (1)

$\mathrm{LiPF}_{6}$ has been observed to thermally decompose at temperatures above $390 \mathrm{~K}[9]$, producing a LiF precipitate and $\mathrm{PF}_{5}$ by the following reaction $[9,10,12]$

$\mathrm{LiPF}_{6} \rightarrow \mathrm{LiF}+\mathrm{PF}_{5}$

The generated $\mathrm{PF}_{5}$ has been suggested to then interact with various components of the electrolyte and undergo a number of possible electrolyte degradation reactions, including: hydrolysis, polymer initiating reactions with EC or other electrolyte molecules, and the generation of undesirable products such as phosphine oxides and alkyl fluorides, among others[10,11,15]. The thermal decomposition of $\mathrm{LiPF}_{6}$ via Reaction (2) and resulting LiF precipitate formation was studied using density functional theory (DFT) molecular dynamics (MD) simulations[12,17], which predicted that highly polar electrolyte molecules, such as the organic liquid carbonates EC, dimethyl carbonate and propylene carbonate, most effectively solvate the $\mathrm{Li}^{+}$and $\mathrm{PF}_{6}^{-}$ion pair compared to other liquid electrolytes. Thus, highly polar organic electrolytes hinder $\mathrm{PF}_{5}$ formation and LiF precipitation by limiting interactions between the two solvated ions. However, if the two ions do react, the LiF product precipitates from the electrolyte onto the electrode surface, which lowers the LiF concentration in the electrolyte and shifts the equilibrium of Reaction (2) towards the $\mathrm{PF}_{5}$ and LiF products.

$\mathrm{PF}_{5}$ produced by Reaction (2) and $\mathrm{H}_{2} \mathrm{O}$ impurities in the electrolyte are expected to play a central role in producing $\mathrm{HF}$ via the reaction[16]

$\mathrm{PF}_{5}+\mathrm{H}_{2} \mathrm{O} \rightarrow \mathrm{POF}_{3}+2 \mathrm{HF}$

$\mathrm{PF}_{5}$ is difficult to isolate in situ during LIB operation, suggesting that it exists in low concentrations because it is either produced in small quantities or that it readily reacts and is consumed[2,4]. NMR and GC-MS characterization of Reaction (1) at temperatures of $358 \mathrm{~K}$ and $373 \mathrm{~K}$ demonstrate that electrolyte degradation is endothermic and slow in organic electrolytes with water impurities[9,17-19]. In addition to the deleterious effect this reaction has on decreasing the concentration of LiPF 6 , it also produces 
$\mathrm{HF}$, which has been suggested to react with lithium transition metal cathodes to degrade them and cause capacity fading in LIBs[2,8,18,20].

In this study, we employed DFT to investigate the mechanisms and energetics of reactions involving electrolyte salt additives that may generate HF. We examined HF generation from Reaction (3) between $\mathrm{PF}_{5}$ with $\mathrm{H}_{2} \mathrm{O}$ and by the analogous reaction between $\mathrm{AsF}_{5}$ and $\mathrm{H}_{2} \mathrm{O}$, where $\mathrm{AsF}_{5}$ is produced along with $\mathrm{LiF}$ in electrolytes utilizing the $\mathrm{LiAsF}_{6}$ additive. Additionally, we studied the formation of $\mathrm{HF}$ by a reaction between $\mathrm{H}_{2} \mathrm{O}$ and $\mathrm{POF}_{3}$, which is produced by Reaction (3). A previous computational study by Okamoto has examined the reaction between $\mathrm{PF}_{5}$ and $\mathrm{H}_{2} \mathrm{O}$ to develop an understanding of the role that $\mathrm{POF}_{3}$ plays in $\mathrm{EC}$ ring opening reactions. [16] Here, we report a comprehensive study of HF formation in the liquid EC electrolytes that results from $\mathrm{H}_{2} \mathrm{O}$ reacting with $\mathrm{PF}_{5}, \mathrm{AsF}_{5}$ or $\mathrm{POF}_{3}$. This study focuses on determining the active mechanisms by which $\mathrm{HF}$ is formed from $\mathrm{H}_{2} \mathrm{O}$ contaminants reacting with various electrolyte salts and developing an understanding of the roles that these reactions might play as well as the effects of bulk EC electrolyte in generating $\mathrm{HF}$ from $\mathrm{PF}_{5}, \mathrm{AsF}_{5}$, and $\mathrm{POF}_{3}$. We investigated the mechanisms of $\mathrm{HF}$ formation resulting from reaction of $\mathrm{PF}_{5}, \mathrm{POF}_{3}$, and $\mathrm{AsF}_{5}$ with $\mathrm{H}_{2} \mathrm{O}$ in EC-based LIB electrolytes as well as interactions between EC solvent molecules and these species, and how these interactions affect HF formation and electrolyte degradation. The study we report examined and compared various routes to HF formation, the effect of Lewis acid-base interactions on electrolyte decomposition as well as the roles of the central atom and the ligands of electrolyte species in HF formation in LIB electrolytes.

\section{Computational Details}

2.1 Molecular DFT Calculations - DFT calculations for examining reactions of the $\mathrm{PF}_{5}, \mathrm{POF}_{3}$, and AsF $\mathrm{A}_{5}$ electrolyte constituents with $\mathrm{H}_{2} \mathrm{O}$ to form $\mathrm{HF}$ were performed using the M06[21] hybrid density functional combined with the 6-31++G(3d,p) basis set[2224] as implemented in the GAMESS computational chemistry software package[25,26]. This basis set was chosen because it reproduces the reaction enthalpies of the $6-311++\mathrm{G}(3 \mathrm{~d}, \mathrm{p})$ triple zeta basis set within $4.2 \mathrm{~kJ} \mathrm{~mol}^{-1}$. The M06 exchange-correlation DFT functional was selected because benchmarking has shown that it accurately reproduces experimental results for fluorine chemistry[27]. The Polarizable Continuum Model (PCM) implicit solvent model, with its parameters set to model EC solvent[28], was employed in all calculations performed to model bulk solvent effects.

For the reactions, all reactant and product structures were verified to have real frequencies, while transition states (TS) were verified to have a single imaginary frequency corresponding to the reaction coordinate determined via an Intrinsic Reaction Coordinate (IRC) calculation. The TS themselves were located using the Quadratic Approximation Method as implemented in GAMESS. See the Supporting Information (SI) for the coordinates of all calculated structures. Frequency calculations were performed at the M06/6-31++(3d,p) level of theory to determine zero point energies (ZPE) and thermal contributions to the enthalpy at $298 \mathrm{~K}$ and $1 \mathrm{~atm}$. Atomic charges were calculated using the CHELPG[29] electrostatic potential derived charges method at the 
M06/6-31++G(3d,p)/PCM-EC level of theory. The bond strengths of the P-F and As-F bonds of the $\mathrm{PF}_{5}, \mathrm{POF}_{3}$, and $\mathrm{AsF}_{5} \mathrm{molecules}$ were determined by calculating their bond dissociation enthalpies (BDE) in PCM modeling EC.

2.2 Use of Explicit Solvent Molecules in Addition to PCM Solvent - Previous studies[11,12,16] on the thermal decomposition of $\mathrm{LiPF}_{6}$ to form $\mathrm{LiF}$ and $\mathrm{PF}_{5}$ via Reaction (2) demonstrate that solvent effects play a significant role in LIB electrolyte chemistry, desirably solvating the reactant ion pair $-\mathrm{Li}^{+}$and $\mathrm{PF}_{6}^{-}-$and facilitating ion transport during operation. Additionally, the high polarity of the EC electrolyte, with a dipole moment of $4.81 \mu / \mathrm{D}[30]$, leads to strong solvent-solvent interactions in addition to electrolyte interactions with $\mathrm{Li}^{+}$and $\mathrm{PF}_{6}^{-}$and other electrolyte impurities. Consequently, to accurately describe HF formation careful consideration of the effects of solvent molecules on the reactions between electrolyte salts and $\mathrm{H}_{2} \mathrm{O}$ is required, which had been neglected in previous studies of the reactions of $\mathrm{PF}_{5}$ with $\mathrm{H}_{2} \mathrm{O}$. The effect of explicit EC solvent molecules on $\mathrm{HF}$ forming reactions is examined below.

When Reaction (2) is calculated using PCM implicit solvent, it is endothermic by $119.2 \mathrm{~kJ} \mathrm{~mol}^{-1}$. However, modeling the solvent with one explicit solvent in addition to implicit solvent lowers the reaction enthalpy to $65.7 \mathrm{~kJ}^{\text {mol }}{ }^{-1}$. Furthermore, adding a second and third explicit EC molecules causes the enthalpy of Reaction (2) to oscillate; it is endothermic by 76.6 and $67.8 \mathrm{~kJ}^{\mathrm{mol}}{ }^{-1}$ when two and three explicit EC molecules are included, respectively. Thus, the reaction enthalpy converges to a value within $\sim 2.1$ $\mathrm{kJ} \mathrm{mol}^{-1}$ of the reaction enthalpy obtained by using only a single explicit EC molecule. This highlights the importance of accurately capturing the solvent interactions that not only significantly affect the stabilities of $\mathrm{Li}^{+}$and the $\mathrm{PF}_{6}^{-}$counter ion, but also affect the stabilities of the $\mathrm{LiF}$ and $\mathrm{PF}_{5}$ products, as demonstrated by this result.

In order to establish an accurate solvation model for calculating the energetics of HF generation in LIB electrolytes we investigated the effect of the solvation model on the reaction of $\mathrm{PF}_{5}$ with $\mathrm{H}_{2} \mathrm{O}$ via Reaction (4)

$\mathrm{PF}_{5}+\mathrm{H}_{2} \mathrm{O} \rightarrow \mathrm{PF}_{4} \mathrm{OH}+\mathrm{HF}$

With the inclusion of an explicit EC solvent molecule, Reaction (4) proceeds through the Lewis acid-base pair reactant complex where an oxygen lone pair of $\mathrm{H}_{2} \mathrm{O}$ donates into an empty $\mathrm{sp}^{3} \mathrm{~d}^{2}$ orbital of the $\mathrm{P}$ center of the $\mathrm{PF}_{5}$. The EC solvent directly affects this reaction to form $\mathrm{HF}$ because it acts as a Lewis base to form the $\mathrm{PF}_{5} \cdot \mathrm{EC}$ complex by donating one of its carbonyl $\mathrm{O}$ lone pairs into the empty $\mathrm{sp}^{3} \mathrm{~d}^{2}$ orbital of $\mathrm{PF}_{5}$. Although this results in a dative complex that has a formation enthalpy similar to that of the $\mathrm{PF}_{5} \cdot \mathrm{H}_{2} \mathrm{O}$ reactant complex, the high concentration of $\mathrm{EC}$ relative to $\mathrm{H}_{2} \mathrm{O}$ significantly lowers the free energy of formation. Consequently, interactions of $\mathrm{EC}$ with the $\mathrm{PF}_{5}$ and $\mathrm{PF}_{4} \mathrm{OH}$ Lewis acids affect the reaction energetics. Thus, we examined Reaction (4) using different solvent models to determine the role of the electrolyte during HF formation.

Similar to Reaction (2), we investigated Reaction (4) with up to three explicit solvating EC molecules in PCM implicit solvent. $\mathrm{PF}_{5}$ first complexes with $\mathrm{H}_{2} \mathrm{O}$ to form the $\mathrm{PF}_{5} \cdot \mathrm{H}_{2} \mathrm{O}$ complex, which converts the $\mathrm{P}$ center from trigonal bipyramidal to a distorted octahedron. $\mathrm{PF}_{5} \cdot \mathrm{H}_{2} \mathrm{O}$ subsequently undergoes ligand exchange to form $\mathrm{HF}$ and $\mathrm{PF}_{4} \mathrm{OH}$ via Reaction (4). When solvation is modeled 
using only implicit solvent, (4) is endothermic by $38.9 \mathrm{~kJ} \mathrm{~mol}^{-1}$ and involves a reaction barrier of $131.4 \mathrm{~kJ} \mathrm{~mol}^{-1}$, as shown in Table 1. Adding an explicit $\mathrm{EC}$ enables the $\mathrm{PF}_{4} \mathrm{OH}$ product with a trigonal bipyramidal $\mathrm{P}$ center to complex with $\mathrm{EC}$ to form the more stable octahedral $\mathrm{PF}_{4} \mathrm{OH} \cdot \mathrm{EC}$ complex. With one explicit EC, (4) is calculated to be endothermic by $14.6 \mathrm{~kJ}^{\mathrm{mol}}{ }^{-1}$ and to occur with a $114.2 \mathrm{~kJ} \mathrm{~mol}^{-1}$ activation barrier. Using three explicit EC molecules results in similar energies with (4) predicted to be endothermic by $11.3 \mathrm{~kJ} \mathrm{~mol}^{-1}$ and to involve a barrier of $115.9 \mathrm{~kJ} \mathrm{~mol}^{-1}$. The slight lowering of the reaction enthalpy by $6.3 \mathrm{~kJ} \mathrm{~mol}^{-1}$ with the addition of three explicit solvating ECs relative to using one explicit EC likely results from the interactions between the solvent molecules themselves, partially overestimating the solvation effect produced by the polar EC-PCM implicit solvent model. These results show that the addition of explicit EC solvent not only stabilizes both the TS and the products relative to the $\mathrm{PF}_{5}$ and $\mathrm{H}_{2} \mathrm{O}$ reactants, but also qualitatively affects the properties of the products.

The equivalent reaction to (4), involving $\mathrm{AsF}_{5}$ and $\mathrm{AsF}_{4} \mathrm{OH}$, proceeds through an analogous pathway. AsF first dative bonds to $\mathrm{H}_{2} \mathrm{O}$ to form an $\mathrm{AsF}_{5} \cdot \mathrm{H}_{2} \mathrm{O}$ complex, which then undergoes ligand exchange to form $\mathrm{HF}$ and $\mathrm{AsF}_{4} \mathrm{OH}$. Including explicit EC in addition to the PCM continuum description of the solvent reduces the reaction energy and barrier to $7.5 \mathrm{~kJ} \mathrm{~mol}^{-1}$ and $49.0 \mathrm{~kJ}^{\mathrm{mol}}{ }^{-1}$, 32.2 and $19.7 \mathrm{~kJ} \mathrm{~mol}^{-1}$ lower than when the solvent is modeled only using implicit solvent. These results demonstrate the necessity of including an explicit solvent molecule in order to accurately capture the solvent effects that affect the energetics of HF generation from $\mathrm{AsF}_{5}$ and $\mathrm{H}_{2} \mathrm{O}$.

We concluded that the effects of including explicit solvent for Reactions (2), (4), and (8) converge with three EC molecules and that a single explicit EC reproduces the results of the model with three explicit EC molecules to within 4 to $8 \mathrm{~kJ} \mathrm{~mol}^{-1}$. Consequently, we employed a single explicit EC molecule in addition to PCM implicit solvent for all calculations examining HF formation reactions with $\mathrm{H}_{2} \mathrm{O}$ because this captures the most relevant solvent effects of the more extensive electrolyte solvent model at a lower computational cost.

\section{Results and Discussion}

3.1 Salt Decomposition and LiF Formation - We examined LiF formation from $\mathrm{LiPF}_{6}$ degradation via Reaction (2), and predict that (2) does not involve a TS and has a reaction enthalpy and barrier of $65.7 \mathrm{~kJ} \mathrm{~mol}^{-1}$. This is consistent with the experimental observation that $\mathrm{PF}_{5}$ forms at temperatures above 390K[9] and suggests that solvation effects play a significant role in LIB electrolyte chemistry, as shown by previous computational studies of LIB electrolytes[11,12,16]. Based on our calculated reaction

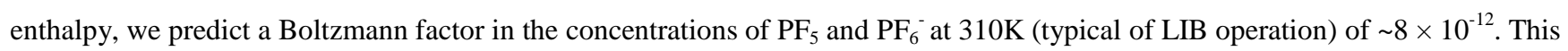
result indicates that (2) does not lead to significant dissociation of $\mathrm{LiPF}_{6}$ because most $\mathrm{LiF}_{\text {and }} \mathrm{PF}_{5}$ that does form by $\mathrm{LiPF}_{6}$ dissociation likely reacts via the reverse of Reaction (2) to reform $\mathrm{LiPF}_{6}$ because the reverse of Reaction (2) is barrierless and exothermic. However, because $\mathrm{LiF}$ is insoluble in the organic electrolyte, precipitation of LiF drives Reaction (2) forward to form 
more $\mathrm{LiF}$ and $\mathrm{PF}_{5}$ than would be expected based purely on the equilibrium of (2), although we expect $\mathrm{PF}_{5}$ to be a low concentration contaminant species[31,32]. We predict that $\mathrm{LiF}$ precipitate formation from $\mathrm{LiPOF}_{4}$ and $\mathrm{LiAsF}_{6}$ also involve no TS and are endothermic by 78.2 and $78.7 \mathrm{~kJ} \mathrm{~mol}^{-1}$ for $\mathrm{LiPOF}_{4}$ and $\mathrm{LiAsF}_{6}$, respectively. Consequently, we expect moderately lower rates of $\mathrm{LiF}$ formation for $\mathrm{LiPOF}_{4}$ and $\mathrm{LiAsF}_{6}$ relative to $\mathrm{LiPF}_{6}$, given the ability of the methods to accurately predict relative reaction barriers and that the pre-exponential factors are comparatively similar.

3.2 $\mathrm{PF}_{5}$ Decomposition and HF Generation - We first examined HF forming reactions that involve the most common electrolyte additive, $\mathrm{LiPF}_{6}$. Following dissociation via Reaction (2), LiF precipitates from the electrolyte[31,32] while $\mathrm{PF}_{5}$ remains solvated. The LUMO of $\mathrm{PF}_{5}$ (see Figure $\mathrm{S} 1$ of the SI) is expected to accept the oxygen electron lone pairs of $\mathrm{H}_{2} \mathrm{O}$, present as an electrolyte contaminant, and EC. That is, $\mathrm{PF}_{5}$ should act as Lewis acid to dative (dipolar) bond with Lewis bases, in particular, $\mathrm{H}_{2} \mathrm{O}$ and $\mathrm{EC}$. The formation of the $\mathrm{PF}_{5} \cdot \mathrm{H}_{2} \mathrm{O}$ Lewis acid-base complex changes the phosphorous coordination in $\mathrm{PF}_{5}$ from a trigonal bipyramidal coordination to a distorted octahedron (with an average F-P-O bond angle of 85.7 degrees). For $\mathrm{PF}_{5} \cdot \mathrm{H}_{2} \mathrm{O}$, we calculated a complexation enthalpy (at $298 \mathrm{~K}$ ) of $-41.8 \mathrm{~kJ} \mathrm{~mol}^{-1}$ and a P-O distance of $1.92 \AA$, indicating the formation of a P-O dative bond. Alternatively, for $\mathrm{PF}_{5} \cdot \mathrm{EC}$ we calculated a complexation enthalpy of $-38.9 \mathrm{~kJ} \mathrm{~mol}^{-1}$ and a P-O distance of $1.83 \AA$, also showing the formation of a dative bond between $\mathrm{PF}_{5}$ and $\mathrm{EC}$.

Our results indicate that although both $\mathrm{H}_{2} \mathrm{O}$ and $\mathrm{EC}$ form favorable complexes with $\mathrm{PF}_{5}$ with similar energies, $\mathrm{PF}_{5}$ primarily complexes with EC due to the high concentration of EC in the electrolyte relative to $\mathrm{H}_{2} \mathrm{O}$. This reduces the rate of $\mathrm{HF}$ generation in the electrolyte by limiting interactions between the $\mathrm{PF}_{5}$ and $\mathrm{H}_{2} \mathrm{O}$ present as a low concentration contaminant. This is of particular importance because degradation of the lithium transition metal oxide cathode by $\mathrm{HF}$ neutralization reactions produces $\mathrm{H}_{2} \mathrm{O}$, which increases its concentration in the electrolyte and thus, increases the rate of HF generation. Additionally, we calculated a charge on the central phosphorus atom of $\mathrm{PF}_{5}$ of $-1.31 \mathrm{e}$, as determined by a CHELPG population analysis and shown in Table 1 , demonstrating that the highly electronegative $\mathrm{F}$ atoms of $\mathrm{PF}_{5}$ withdraw electron density from the $\mathrm{P}$ center to make it highly electrophilic and likely to interact favorably with the lone pairs of EC or $\mathrm{H}_{2} \mathrm{O}$.

Following formation of the $\mathrm{PF}_{5} \cdot \mathrm{H}_{2} \mathrm{O}$ complex, two $\mathrm{HF}$ molecules form according to Reaction (3). However, we find that Reaction (3) occurs as two sequential proton transfer reactions, Reactions (4) and (5), to form two HF molecules. We first examined Reaction (4), the ligand exchange reaction that converts $\mathrm{PF}_{5} \cdot \mathrm{H}_{2} \mathrm{O}$ into $\mathrm{HF}$ and $\mathrm{PF}_{4} \mathrm{OH}$. We calculate the $\mathrm{BDE}$ of $\mathrm{PF} 5$ is $560.7 \mathrm{~kJ}$ $\mathrm{mol}^{-1}$, which is in agreement with previous computational results[33]. Our results predict that Reaction (4) is endothermic with a

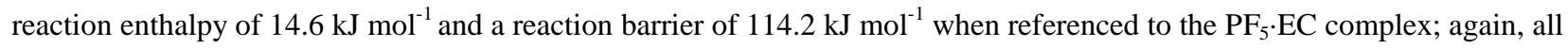
reactions include one explicit EC molecule in addition to the PCM continuum solvent model. The low concentrations of both the $\mathrm{PF}_{5}$ and $\mathrm{H}_{2} \mathrm{O}$ and the $114.2 \mathrm{~kJ} \mathrm{~mol}^{-1}$ activation barrier suggest that Reaction (4) to decompose $\mathrm{PF}_{5}$ into $\mathrm{PF}_{4} \mathrm{OH}$ and $\mathrm{HF}$ is sluggish, 
even at temperatures realized in LIBs during operation. This is corroborated by the experimental observation that significant capacity loss from HF attack occurs over a time scale of months in LIBs that employ carbonate electrolytes with LiPF $_{6}$ additives $^{13}$. Additionally, we expect $\mathrm{PF}_{5}$ to exist in the electrolyte predominantly as a $\mathrm{PF}_{5} \cdot \mathrm{EC}$ complex, rather than as the uncomplexed, solvated species of our reference calculations. From the $\mathrm{PF}_{5} \cdot \mathrm{EC}$ complex with a solvating $\mathrm{H}_{2} \mathrm{O}$ molecule we calculate a reaction barrier of $114.2 \mathrm{~kJ} \mathrm{~mol}^{-1}$ and a reaction enthalpy of $14.6 \mathrm{~kJ} \mathrm{~mol}^{-1}$, as shown in Figure 1.

As (4) proceeds from the reactant complex through the TS, as shown in Figure $2 \mathrm{a}$, the P-O bond distance decreases from $1.92 \AA$ to $1.73 \AA$, while the P-F bond distance of the P-F bond undergoing dissociation increases from $1.60 \AA$ to $1.95 \AA$. This is characteristic of a ligand exchange reaction and demonstrates the simultaneous transformation of the P-O dative bond into a covalent bond and dissociation of a P-F bond, which occurs by proton transfer from the $\mathrm{O}$ of $\mathrm{H}_{2} \mathrm{O}$ to a $\mathrm{F}$ of $\mathrm{PF}_{5}$ to form $\mathrm{HF}$, as shown in Figure $2 \mathrm{~b}$. Analysis of the product state structures shows that the $\mathrm{O}-\mathrm{H}$ distance between the $\mathrm{H}$ of $\mathrm{HF}$ and the $\mathrm{O}$ of the $\mathrm{OH}$ ligand increases to $1.24 \AA$, indicating that it is now a hydrogen bond rather than an $\mathrm{O}-\mathrm{H}$ covalent bond. Meanwhile, the distance between the $\mathrm{H}$ and $\mathrm{F}$ atoms decreases from 2.29 in $\mathrm{PF}_{5} \cdot \mathrm{H}_{2} \mathrm{O}$ to $1.14 \AA$ in $\mathrm{PF}_{4} \mathrm{OH} \cdot \mathrm{EC}$ - indicating the formation of $\mathrm{HF}$. As the P-F bond dissociates, the $\mathrm{P}$-center returns to the five-fold coordination it possessed in $\mathrm{PF}_{5}$, which allows $\mathrm{P}$ in $\mathrm{PF}_{4} \mathrm{OH}$ to again act as a Lewis acid. Thus, $\mathrm{PF}_{4} \mathrm{OH}$ complexes with the explicit solvating EC to form the $\mathrm{PF}_{4} \mathrm{OH} \cdot \mathrm{EC}$ Lewis Acid-Base pair, in which EC acts as a Lewis base and $\mathrm{PF}_{4} \mathrm{OH}$ acts as a Lewis acid in which the octahedrally coordinated $\mathrm{P}$ accepts the oxygen lone pair from the EC carbonyl. The dative bond stabilizes the $\mathrm{PF}_{4} \mathrm{OH} \cdot \mathrm{EC}$ product to reduce the reaction enthalpy to generate HF by Reaction (4) (see Computational Details for an analysis of the effects of EC on Reaction (4)). These results predict that the EC electrolyte has a moderate catalytic effect on this reaction. Thus, while EC's polarity is desirable in improving the solvation of $\mathrm{Li}^{+}$to facilitate its transport in the electrolyte, its ability to form a Lewis acid-base complex promotes degradation of the electrolyte salt and formation of HF. Figure 3 shows the $\mathrm{PF}_{4} \mathrm{OH} \cdot \mathrm{EC}$ product complex, which we verified using an IRC analysis that confirms that the TS shown in Figure 2 connects it with $\mathrm{PF}_{5} \cdot \mathrm{H}_{2} \mathrm{O}$. Additionally, our results predict that the HF produced from Reaction (4) is hydrogen bonded to the $\mathrm{O}$ in the $\mathrm{PF}_{4} \mathrm{OH} \cdot \mathrm{EC}$ complex, and dissociation of this $\mathrm{PF}_{4} \mathrm{OH} \cdot \mathrm{EC}-\mathrm{HF}$ product to form $\mathrm{PF}_{4} \mathrm{OH} \cdot \mathrm{EC}$ and a solvated $\mathrm{HF}$ is endothermic by only $8.8 \mathrm{~kJ} \mathrm{~mol}^{-1}$, which is thermally accessible at room temperature. The above results show that Reaction (4) is the first HF formation step of $\mathrm{PF}_{5}$ decomposition and $\mathrm{HF}$ generation in the overall reaction (3).

Reaction (5) forms $\mathrm{HF}$ by decomposition of the $\mathrm{PF}_{4} \mathrm{OH} \cdot \mathrm{EC}$ complex by a subsequent proton transfer reaction analogous to Reaction (4); this is the second step in the two-step mechanism of $\mathrm{PF}_{5}$ degradation by reaction with $\mathrm{H}_{2} \mathrm{O}$ that comprises Reaction (3). We next investigated whether Reaction (5),

$\mathrm{PF}_{4} \mathrm{OH} \rightarrow \mathrm{PF}_{3} \mathrm{O}+\mathrm{HF}$

is an active route to forming additional $\mathrm{HF}$. 
Our calculations predict that (5) proceeds through an activation barrier of $97.5 \mathrm{~kJ} \mathrm{~mol}^{-1}$ and is endothermic by $1.3 \mathrm{~kJ} \mathrm{~mol}^{-1}$ relative to the $\mathrm{PF}_{4} \mathrm{OH} \cdot \mathrm{EC}$ reactant complex, as shown in Figure 3. At the TS (shown in Figure 4), the EC molecule has dissociated from the $\mathrm{PF}_{4} \mathrm{OH} \cdot \mathrm{EC}$ reactant complex, increasing the $\mathrm{P}-\mathrm{O}$ distance to $3.21 \AA$, and the $\mathrm{P}-\mathrm{F}$ bond has partially dissociated by lengthening to $2.17 \AA$. Dissociation of the P-F bond results in $\mathrm{POF}_{3}$ with a tetrahedral coordination and with $\mathrm{HF}$ hydrogen bonded to its oxygen atom. However, $\mathrm{POF}_{3}$ does not form a dative complex with $\mathrm{EC}$ or $\mathrm{H}_{2} \mathrm{O}$, which would involve a significant energy penalty to hybridize with the P $3 \mathrm{~d}$ orbitals while only enabling the formation of a relatively weak dative bond. Consequently, although Reactions (4) and (5) are both proton transfer reactions that dissociate P-F and O-H bonds to form HF, (5) differs from (4) in that the $\mathrm{POF}_{3}$ resulting from (5) does not complex with $\mathrm{EC}$ and is tetrahedral, whereas the $\mathrm{PF}_{4} \mathrm{OH} \cdot \mathrm{EC}$ product resulting from (4) does complex with EC and is octahedral. Dissociation of HF from the product complex of Reaction (5) to form a solvated HF only involves breaking a hydrogen bond and only requires $13.4 \mathrm{~kJ} \mathrm{~mol}^{-1}$. The schematic potential energy surface (PES) of the two-step decomposition of $\mathrm{PF}_{5}$ by reaction with $\mathrm{H}_{2} \mathrm{O}$ to form $\mathrm{POF}_{3}$ and two $\mathrm{HF}$ molecules is shown in Figure 1.

$\mathrm{PF}_{5}$ and $\mathrm{PF}_{4} \mathrm{OH}$ are both Lewis acids and form relatively stable Lewis acid-base complexes with $\mathrm{H}_{2} \mathrm{O}$ and EC through their oxygen lone pairs with complexation enthalpies of $-41.8,-38.9$, and $-20.1 \mathrm{~kJ} \mathrm{~mol}^{-1}$ for $\mathrm{PF}_{5} \cdot \mathrm{H}_{2} \mathrm{O}, \mathrm{PF}_{5} \cdot \mathrm{EC}$, and $\mathrm{PF} 4 \mathrm{OH} \cdot \mathrm{EC}_{\text {, }}$ respectively. The reaction of $\mathrm{PF}_{5}$ with $\mathrm{H}_{2} \mathrm{O}$ to form two $\mathrm{HF}$ molecules (3) involves barriers for both steps - Reactions (4) and (5) as shown in Figure 1. The first step, Reaction (4), has a larger barrier (114.2 kJ mol $\left.{ }^{-1}\right)$ than Reaction (5) (97.1 kJ mol $\left.{ }^{-1}\right)$ and is thus the rate-limiting step for $\mathrm{HF}$ generation by this mechanism. These results indicate that the concentration of $\mathrm{PF}_{4} \mathrm{OH}$ in the electrolyte is low because it is an intermediate product formed by the rate-limiting step and is rapidly transformed into the products through a lower barrier step. Our calculations predict that $\mathrm{PF}_{5}$ reacts with $\mathrm{H}_{2} \mathrm{O}$ to generate $\mathrm{HF}$, especially at elevated operating temperatures. However, the barrier to these reactions is relatively high, while the concentration of $\mathrm{H}_{2} \mathrm{O}$ is low and $\mathrm{H}_{2} \mathrm{O}$ must compete with EC to form the initial reactant complex. The relatively slow generation of HF predicted by these results is consistent with experimental observation $[13,16]$.

3.3 $\mathrm{POF}_{3}$ Decomposition and HF Generation $-\mathrm{POF}_{3}$ is the product of $\mathrm{PF}_{5}$ hydrolysis via Reactions (4) and (5) and has been suggested to further react with $\mathrm{H}_{2} \mathrm{O}$ impurities to generate additional $\mathrm{HF}$, which reacts with the cathode to reduce LIB service lifetimes[11,15]. However, $\mathrm{POF}_{3}$ is a weak Lewis acid compared to $\mathrm{PF}_{5}$ and - as mentioned above - does not dative bond to EC or $\mathrm{H}_{2} \mathrm{O}$ in our calculations, in contrast to $\mathrm{PF}_{4} \mathrm{OH} \cdot \mathrm{EC}$. This is a result of the relatively weak dative bonds not providing sufficient stabilization to compensate for the promotion energy required to form $\mathrm{sp}^{3} \mathrm{~d}^{2}$ hybridized orbitals, whereas the P-O covalent bond with the $\mathrm{OH}$ ligand in $\mathrm{PF}_{4} \mathrm{OH} \cdot \mathrm{EC}$ is strong enough to stabilize the hybridization required to form $\mathrm{PF}_{4} \mathrm{OH}$, which possesses an empty sp $\mathrm{d}^{2}$ orbital to accept the carbonyl lone pair of EC. Consequently, the $\mathrm{P}$ center of $\mathrm{POF}_{3}$ does not act as an acceptor for the oxygen lone pairs of either $\mathrm{EC}$ or $\mathrm{H}_{2} \mathrm{O}$, in contrast to our predictions for $\mathrm{PF}_{5}$ described above. Additionally, we calculated a $595.8 \mathrm{~kJ}$ mol ${ }^{-1} \mathrm{BDE}$ for the $\mathrm{P}-\mathrm{F}$ bond in $\mathrm{POF}_{3}, 35.1 \mathrm{~kJ} \mathrm{~mol}^{-1}$ greater than for the $\mathrm{P}-\mathrm{F}$ bond in $\mathrm{PF}_{5}$, as shown in Table 2. This suggests that $\mathrm{HF}$ generation 
from $\mathrm{POF}_{3}$ degradation involves greater energetic barriers than $\mathrm{HF}$ generation from $\mathrm{PF}_{5}$. Consequently, we examined the reaction of $\mathrm{POF}_{3}$ with $\mathrm{H}_{2} \mathrm{O}$ to determine whether this reaction is a kinetically viable route for HF formation.

Reaction of $\mathrm{H}_{2} \mathrm{O}$ with $\mathrm{POF}_{3}$ to form two $\mathrm{HF}$ molecules might occur via two subsequent ligand exchange reactions, analogous to the mechanism of $\mathrm{HF}$ formation by reaction of $\mathrm{H}_{2} \mathrm{O}$ with $\mathrm{PF}_{5}$. The first step in this reaction to form $\mathrm{HF}$ is

$\mathrm{POF}_{3}+\mathrm{H}_{2} \mathrm{O} \rightarrow \mathrm{POF}_{2} \mathrm{OH}+\mathrm{HF}$

We calculate a lower positive charge on the central $\mathrm{P}$ atom of $\mathrm{POF}_{3}(1.19 \mathrm{e})$ compared to $\mathrm{PF}_{5}(1.31 \mathrm{e})$, as expected given the higher electronegativity of $\mathrm{F}$ relative to $\mathrm{O}$ and that $\mathrm{PF}_{5}$ has five $\mathrm{F}$ ligands. This suggests that the $\mathrm{P}$ of $\mathrm{POF}_{3}$ is less electrophilic than the $\mathrm{P}$ of $\mathrm{PF}_{5}$. Furthermore, $\mathrm{POF}_{3}$ is tetrahedrally coordinated and its $\mathrm{P}$ is $\mathrm{sp}^{3}$ hybridized while $\mathrm{PF}_{5}$ is bipyrimidal and its $\mathrm{P}$ is $\mathrm{sp}^{3} \mathrm{~d}^{2}$ hybridized. As a result, and in contrast to $\mathrm{PF}_{5}, \mathrm{POF}_{3}$ does not possess a low lying LUMO to accept the oxygen lone pairs of $\mathrm{H}_{2} \mathrm{O}$ or EC to form stable dative bonded complexes with them. Furthermore, the $\mathrm{LUMO}_{\text {of }} \mathrm{POF}_{3}$ (see Figure $\mathrm{S} 1$ of the SI) is more diffuse than that of $\mathrm{PF}_{5}$, suggesting that a higher degree of spatial overlap exists between the $\mathrm{POF}_{3} \mathrm{LUMO}$ and the $\mathrm{HOMO}$ of EC or $\mathrm{H}_{2} \mathrm{O}$, which in both cases is an oxygen lone pair. We also calculate that the LUMO of $\mathrm{POF}_{3}$ lies $102.1 \mathrm{~kJ}^{\text {mol }}{ }^{-1}$ higher in energy than the LUMO of $\mathrm{PF}_{5}$, as shown in Table 2, also suggesting that $\mathrm{POF}_{3}$ is a poor Lewis acid and should form weaker Lewis acid-base complexes with $\mathrm{EC}$ and $\mathrm{H}_{2} \mathrm{O}$ than $\mathrm{PF}_{5}$, if it dative bonds at all. Our calculations confirm this. Optimization of the IRC reactant complex results in the reactants approaching two separated solvated species, with the P-O distance of $2.98 \AA$ between $\mathrm{POF}$ and $\mathrm{H}_{2} \mathrm{O}$, indicating only a weak electrostatic interaction rather than the formation of a dative bond. Consequently, we expect the reactants of Reaction (6) will preferentially remain isolated as solvated electrolyte species rather than form a $\mathrm{POF}_{3} \cdot \mathrm{H}_{2} \mathrm{O}$ reactant complex - in contrast to the formation of the $\mathrm{PF}_{5} \cdot \mathrm{H}_{2} \mathrm{O}$ complex.

We have calculated Reaction (6) of $\mathrm{POF}_{3}$ with $\mathrm{H}_{2} \mathrm{O}$ to produce $\mathrm{HF}$ and $\mathrm{POF}_{2} \mathrm{OH}$. The schematic PES for Reaction (6) is shown in Figure 1. We find that (6) proceeds through a TS lying $157.7 \mathrm{~kJ} \mathrm{~mol}^{-1}$ above the separated, solvated reactants; $43.5 \mathrm{~kJ}$ mol ${ }^{-1}$ higher than the barrier to form $\mathrm{HF}$ from $\mathrm{PF}_{5}$, via Reaction (4). The reaction is approximately thermalneutral with a calculated enthalpy of reaction that is exothermic by only $3.8 \mathrm{~kJ} \mathrm{~mol}^{-1}$ relative to the isolated reactants, whereas Reaction (4) was endothermic by $14.6 \mathrm{~kJ} \mathrm{~mol}^{-1}$. The increase in activation barrier for $\mathrm{HF}$ formation reduces the Boltzmann factor in the rate constant at $310 \mathrm{~K}$ by $4.7 \times 10^{-8}$ relative to that of Reaction (4). In addition, the TS - shown in Figure 5 - of Reaction (6) has longer P-F and H-F bonds

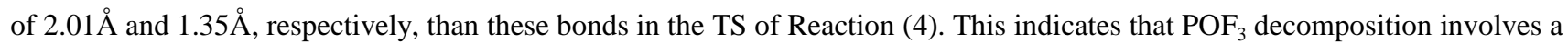
late TS and a higher barrier, which is a result of the increase in the bond strength of the P-F bond of $\mathrm{POF}_{3}$ compared to the P-F bond of $\mathrm{PF}_{5}$. The higher predicted barrier and associated slower HF formation kinetics results in a significant improvement over the current state-of-the-art salt additive, $\mathrm{PF}_{6}^{-}$. Consequently, degradation of a $\mathrm{POF}_{3}$ electrolyte constituent by reaction with $\mathrm{H}_{2} \mathrm{O}$ is predicted to result in significantly slower formation rates of $\mathrm{HF}$ and $\mathrm{POF}_{2} \mathrm{OH}$ compared to $\mathrm{PF}_{5}$ degradation. 
As expected, Reaction (6) does not produce a dative complex between $\mathrm{POF}_{2} \mathrm{OH}$ and $\mathrm{EC}$, in contrast to the $\mathrm{PF}_{4} \mathrm{OH} \cdot \mathrm{EC}$ complex formed by Reaction (4) that stabilizes the products and thus enhances HF formation. The P center of $\mathrm{POF}_{3}$ transitions from tetrahedral to five-fold coordination as Reaction (6) proceeds to the TS, and returns to being tetrahedrally coordinated in the $\mathrm{POF}_{2} \mathrm{OH}$ product state. Consequently, the TS involves the energetic penalty of mixing in the P $3 \mathrm{~d}$ orbitals, explaining the higher barrier than that of Reaction (4). Similar to $\mathrm{POF}_{3}$, the $\mathrm{P}$ of $\mathrm{POF}_{2} \mathrm{OH}$ is $\mathrm{sp}^{3}$ coordinated and does not possess an empty orbital to accept lone pairs from either $\mathrm{H}_{2} \mathrm{O}$ or EC. Optimization of a contact complex between $\mathrm{POF}_{2} \mathrm{OH}$ and $\mathrm{EC}$ results in the two components drifting apart towards separate, solvated species with a P-O distance of $3.11 \AA$, indicating that $\mathrm{POF}_{2} \mathrm{OH}$, like $\mathrm{POF}_{3}$, does not act as a Lewis acid to complex with $\mathrm{EC}$ or $\mathrm{H}_{2} \mathrm{O}$. It has been previously reported that $\mathrm{POF}_{2} \mathrm{OH}$ may subsequently react sequentially with two additional $\mathrm{H}_{2} \mathrm{O}$ molecules to form $\mathrm{H}_{3} \mathrm{PO}_{4}$ and two $\mathrm{HF}$ molecules[34]. However, both $\mathrm{POF}_{2} \mathrm{OH}$ and $\mathrm{H}_{2} \mathrm{O}$ as a contaminant are present in the electrolyte at very low concentrations, and thus, these reactions are unlikely. Consequently, we limit our investigation of further HF formation to the self-decomposition of $\mathrm{POF}_{2} \mathrm{OH}$, analogous to the above case of $\mathrm{PF}_{4} \mathrm{OH}$ dissociation by Reaction (5). Although formation of $\mathrm{POF}_{2} \mathrm{OH}$ involves a significantly higher barrier than Reaction (4), we also examined HF formation as a result of dissociation of the $\mathrm{POF}_{2} \mathrm{OH}$ product of Reaction (6).

Although formation of $\mathrm{POF}_{2} \mathrm{OH}$ involves a significantly higher barrier than Reaction (4), we also examined $\mathrm{HF}$ formation as a result of dissociation of the $\mathrm{POF}_{2} \mathrm{OH}$ product of Reaction (6). This HF formation proceeds via the following reaction $\mathrm{POF}_{2} \mathrm{OH} \rightarrow \mathrm{PO}_{2} \mathrm{~F}+\mathrm{HF}$

We predict that Reaction (7) proceeds through an activation barrier of $141.4 \mathrm{~kJ} \mathrm{~mol}^{-1}$ and is endothermic by $73.6 \mathrm{~kJ}$ mol ${ }^{-1}$. The TS of Reaction (7), shown in Figure 6 , is stabilized by formation of a complex between $\mathrm{PO}_{2} \mathrm{~F}$ and an EC solvent molecule, while the TS of Reaction (5) was predicted to not form a complex. The barrier for Reaction (7) is only $3.8 \mathrm{~kJ}^{\text {mol }}{ }^{-1}$ lower than the first activation barrier, which suggests that within the resolution of our model and method, either Reaction (6) or (7) will be ratelimiting. Although our calculations show that an $\mathrm{EC}$ donates a carbonyl oxygen lone pair to the $\mathrm{P}$ atom at the $\mathrm{TS}$ and product $\mathrm{PO}_{2} \mathrm{~F}$ to create a tetrahedral P center and stabilize the TS and products, the barrier and endothermicity are still relatively high. Our calculations predict that the length of the P-O dative bond that forms as the reaction proceeds increases from $1.54 \AA$ at the TS to $1.74 \AA$ at the product state, indicating that EC stabilizes the TS of Reaction (7). The higher activation energies reduces the Boltzmann factors in the rate constants of Reactions (7) and (5) by $4.0 \times 10^{-8}$ at $310 \mathrm{~K}$. Thus, we expect significantly lower rates of HF formation from reaction of $\mathrm{H}_{2} \mathrm{O}$ with $\mathrm{POF}_{3}$ than with $\mathrm{PF}_{5}$, possibly allowing a battery with $\mathrm{POF}_{3}$ electrolyte species to operate without significant $\mathrm{HF}$ formation. As a result, we recommend investigating $\mathrm{LiPOF}_{4}-$ a potential electrolyte salt comprised of $\mathrm{Li}^{+}$ and $\mathrm{POF}_{4}^{-}$- as an alternative to $\mathrm{LiPF}_{6}$ for use in $\mathrm{LIBs}$. LiPOF 4 has been reported to be inexpensive to synthesize[35], and while LiF formation may still occur for $\mathrm{LiPOF}_{4}$ in a similar manner to Reaction (1), $\mathrm{POF}_{3}$ would be formed rather than $\mathrm{PF}_{5}$, which we expect would lead to reduced electrolyte and cathode degradation. 
3.4 $\mathrm{AsF}_{5}$ Decomposition and HF Generation - In addition to investigating $\mathrm{PF}_{5}$ and $\mathrm{POF}_{3}$, we also studied $\mathrm{HF}$ generation resulting from reaction between $\mathrm{H}_{2} \mathrm{O}$ and $\mathrm{AsF}_{5}$, which would be produced from decomposition of the potential electrolyte additive LiAsF 6 analogous to Reaction (1). $\mathrm{LiAsF}_{6}$ is a salt comprised of $\mathrm{Li}^{+}$and $\mathrm{AsF}_{6}{ }^{-}$and was studied alongside $\mathrm{LiPF}_{6}$ as an electrolyte additive and showed improvements in LIB operation similar to $\mathrm{LiPF}_{6}$, but has not been used in commercial LIBs due to concerns about the toxicity of As. We predict that $\mathrm{LiAsF}_{6}$ dissociates into $\mathrm{LiF}$ and $\mathrm{AsF}_{5}$ with a reaction enthalpy of $78.7 \mathrm{~kJ}^{\text {mol }}{ }^{-1}$, similar to the energy to form $\mathrm{LiF}$ and $\mathrm{POF}_{3}$ in an $\mathrm{EC}$ electrolyte from $\mathrm{LiPOF}_{4}$, and $\sim 13 \mathrm{~kJ} \mathrm{~mol}^{-1}$ higher than the enthalpy to form $\mathrm{LiF}$ from $\mathrm{LiPF}$. Similar to the cases of $\mathrm{PF}_{5}$ and $\mathrm{POF}_{3}$, we examined $\mathrm{HF}$ generation as a result of a ligand exchange reaction between the AsF 5 and $\mathrm{H}_{2} \mathrm{O}$.

Our calculations show that $\mathrm{HF}$ generation from $\mathrm{AsF}_{5}$ is characterized by the formation of a strong $\mathrm{AsF}_{5} \cdot \mathrm{H}_{2} \mathrm{O}$ dative complex, which converts the As center from the trigonal bipyramidal coordination of $\mathrm{AsF}_{5}$ to a distorted octahedral coordination, similar to the $\mathrm{PF}_{5} \cdot \mathrm{H}_{2} \mathrm{O}$ Lewis acid-base complex for Reaction (4). We predict a $448.9 \mathrm{~kJ} \mathrm{~mol}^{-1} \mathrm{BDE}$ for the As-F bond of AsF $5,111.7 \mathrm{~kJ}$ mol ${ }^{1}$ lower than the BDE for the P-F bond in $\mathrm{PF}_{5}$.

A population analysis predicts that the charges on the $\mathrm{As}$ and $\mathrm{P}$ centers of $\mathrm{AsF}_{5}$ and $\mathrm{PF}_{5}$ are 1.40 e and $1.31 \mathrm{e}$, respectively. Thus, the F atoms withdraw more electron density from the As center compared to the $\mathrm{P}$ center, creating a more electropositive As center. Additionally, a comparison of the HOMO-LUMO gap of the $\mathrm{PF}_{5}, \mathrm{POF}_{3}$, and $\mathrm{AsF}_{5}$ species, shown in Table 1 , demonstrates a

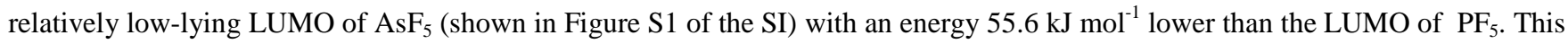
allows for a closer energetic overlap between the oxygen lone pairs and the LUMO. Consequently, we expect $\mathrm{AsF}_{5}$ to act as a stronger Lewis acid than $\mathrm{PF}_{5}$ and form stronger dative complexes with EC and $\mathrm{H}_{2} \mathrm{O}$. Our calculations confirm this hypothesis; the formation of the $\mathrm{AsF}_{5} \cdot \mathrm{H}_{2} \mathrm{O}$ complex is exothermic by $81.2 \mathrm{~kJ} \mathrm{~mol}^{-1}$, nearly $42 \mathrm{~kJ} \mathrm{~mol}^{-1}$ more stable than the $\mathrm{PF}_{5} \cdot \mathrm{H}_{2} \mathrm{O}$ complex. Furthermore, we calculated an As-O bond distance for $\mathrm{AsF}_{5} \cdot \mathrm{H}_{2} \mathrm{O}$ of $1.99 \AA$, indicating the formation of an As-O dative bond. In addition to complexing with $\mathrm{H}_{2} \mathrm{O}, \mathrm{AsF}_{5}$ will also complex with $\mathrm{EC}$ to form $\mathrm{AsF}_{5} \cdot \mathrm{EC}$; the formation of the $\mathrm{AsF} \mathrm{F}_{5} \cdot \mathrm{EC}$ complex is exothermic by $62.8 \mathrm{~kJ} \mathrm{~mol}^{-1}$, as shown in Figure 1 . However, the concentration of EC is $\sim 10^{5}$ times higher than that of $\mathrm{H}_{2} \mathrm{O}$ in $\mathrm{LIB}$ electrolytes so that an $18.4 \mathrm{~kJ} \mathrm{~mol}^{-1}$ more stable complex does not lead to $\mathrm{H}_{2} \mathrm{O}$ outcompeting EC to complex with AsF $\mathrm{F}_{5}$ Thus, we expect $\mathrm{AsF}_{5}$ to be primarily complexed with $\mathrm{EC}$, which reduces the rate of $\mathrm{HF}$ formation in electrolytes that utilize the $\mathrm{AsF}_{6}{ }^{-} \mathrm{counter}^{-}$ ion.

After formation of the $\mathrm{AsF}_{5} \cdot \mathrm{H}_{2} \mathrm{O}$ complex, the ligand exchange reaction leads to formation of $\mathrm{HF}$ and AsF $\mathrm{F}_{5}$ degradation through $\mathrm{AsF}_{5}+\mathrm{H}_{2} \mathrm{O} \rightarrow \mathrm{AsF}_{4} \mathrm{OH}+\mathrm{HF}$

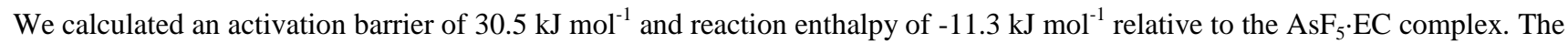
low barrier ensures that this reaction is fast, even without the possibility that the transient non-equilibrium partitioning of excess energy from complex formation will be deposited into the reaction coordinate. The lower activation barrier for HF formation from 
the ligand exchange between $\mathrm{H}_{2} \mathrm{O}$ and $\mathrm{AsF}_{5}$ relative to the reactions between $\mathrm{H}_{2} \mathrm{O}$ and both $\mathrm{PF}_{5}$ and $\mathrm{POF}_{3}$ results from the lower As$\mathrm{F}$ bond enthalpy relative to that of $\mathrm{P}-\mathrm{F}$ in $\mathrm{PF}_{5}$ and $\mathrm{POF}_{3}$.

Our results predict that $\mathrm{EC}$ dative bonds with the $\mathrm{AsF}_{4} \mathrm{OH}$ product of Reaction (8) to stabilize it by forming an $\mathrm{AsF} \mathrm{F}_{4} \mathrm{OH} \cdot \mathrm{EC}$ complex (see Computational Details for an analysis of the effect of EC on Reaction (8)). This complex maintains an octahedral coordination of the As center upon reaction and drives Reaction (8) forward, analogous to the stabilization of the $\mathrm{PF}_{4} \mathrm{OH} \cdot \mathrm{EC}$ product of Reaction (4). These comparisons show that interactions with the EC electrolyte stabilize the TS and products of (8) relative to the reactant state and thus lower the activation barrier and predict a reaction that is exothermic rather than endothermic. Additionally, the HF formed by Reaction (8) is hydrogen bonded to the $\mathrm{O}$ in the $\mathrm{AsF}_{4} \mathrm{OH} \cdot \mathrm{EC}$ complex, and we predict a dissociation enthalpy of $10.0 \mathrm{~kJ} \mathrm{~mol}^{-1}$ to solvate the $\mathrm{HF}$ from this $\mathrm{AsF}_{4} \mathrm{OH} \cdot \mathrm{EC}-\mathrm{HF}$ complex. Our results show that AsF $\mathrm{F}_{5}$ readily reacts with $\mathrm{H}_{2} \mathrm{O}$ by a ligand exchange reaction through proton transfer to form $\mathrm{HF}$ and an $\mathrm{AsF}_{4} \mathrm{OH} \cdot \mathrm{EC}$ complex.

The $\mathrm{AsF}_{4} \mathrm{OH} \cdot \mathrm{EC}$ produced by Reaction (8) can itself undergo decomposition to form additional HF via another proton transfer reaction

$\mathrm{AsF}_{4} \mathrm{OH} \rightarrow \mathrm{AsOF}_{3}+\mathrm{HF}$

Similar to the case of Reaction (5), which produced $\mathrm{HF}$ by reaction of $\mathrm{PF}_{5}$ with $\mathrm{H}_{2} \mathrm{O}$, our calculations predict that EC dissociates from $\mathrm{AsF}_{4} \mathrm{OH} \cdot \mathrm{EC}$ with a dissociation enthalpy of $-62.3 \mathrm{~kJ} \mathrm{~mol}^{-1}$ and that the resulting $\mathrm{AsF}_{4} \mathrm{OH}$ undergoes an intramolecular proton transfer form $\mathrm{HF}$ and $\mathrm{AsOF}_{3}$. Reactions (8) and (9) make up a two-step reaction that converts $\mathrm{AsF}_{5}$ with $\mathrm{H}_{2} \mathrm{O}$ into $\mathrm{AsOF}$ and two HF molecules. However, we calculate a barrier and reaction enthalpy for Reaction (9) of $158.6 \mathrm{~kJ} \mathrm{~mol}^{-1}$ and $117.2 \mathrm{~kJ} \mathrm{~mol}^{-1}$, respectively, as shown in Figure 1. Although $\mathrm{AsF}_{5}$ reacts with $\mathrm{H}_{2} \mathrm{O}$ to rapidly form $\mathrm{HF}$ and $\mathrm{AsF}_{4} \mathrm{OH}$ via (8), subsequent reaction by (9) to generate a second HF occurs with a barrier of $158.6 \mathrm{~kJ} \mathrm{~mol}^{-1}$, which is inactive at the typical temperatures realized in LIBs. Due to the high barrier of the second reaction step, $\mathrm{AsF}_{4} \mathrm{OH} \cdot \mathrm{EC}$ complexes and a single $\mathrm{HF}$ molecule would predominantly form in electrolytes containing $\mathrm{LiAsF}_{6}$, as $\mathrm{AsF}_{4} \mathrm{OH} \cdot \mathrm{EC}$ is the first stable intermediate on the PES and is formed via a low barrier reaction and converted to $\mathrm{AsOF}_{3}$ and a second $\mathrm{HF}$ molecule via a high barrier reaction. Consequently, our results predict that electrolytes with $\mathrm{LiAsF}_{6}$ replacing $\mathrm{LiPF}_{6}$ will have lower concentrations of $\mathrm{HF}$ than LIBs utilizing $\mathrm{LiPF}_{6}-$ because $\mathrm{PF}_{5}$ reacts with $\mathrm{H}_{2} \mathrm{O}$ to form two HF molecules rather than just one - but higher HF concentrations than those utilizing LiPOF $_{4}$ as the electrolyte salt additive, where the first step to form HF possesses a high barrier and is kinetically inactive at operating conditions.

\section{Conclusions}

In this study, we examined HF generation in lithium ion battery electrolytes from reactions between $\mathrm{H}_{2} \mathrm{O}$ contaminants and the decomposition products $\mathrm{PF}_{5}, \mathrm{POF}_{4}$ and $\mathrm{AsF}_{5}$ of the three electrolyte additives $\mathrm{LiPF}_{6}, \mathrm{LiPOF}_{4}$, and $\mathrm{LiAsF}_{6}$. The initial precipitation of $\mathrm{LiF}$ from these additives to form $\mathrm{PF}_{5}, \mathrm{POF}_{3}$ and $\mathrm{AsF}_{5}$ from these salts has been previously shown to be dominated by the choice 


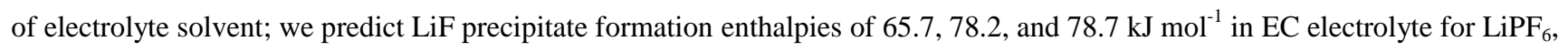
$\mathrm{LiPOF}_{4}$, and LiAsF 6 , respectively. We investigated the ligand exchange reaction mechanisms between the LiF precipitate products: $\mathrm{PF}_{5}, \mathrm{POF}_{3}$, and $\mathrm{AsF}_{5}$, and $\mathrm{H}_{2} \mathrm{O}$ to form $\mathrm{HF}$ in the electrolyte, which subsequently reacts with transition metal oxide cathodes to degrade them and shorten LIB lifetimes.

We predict significant Lewis acid-base interactions between the $\mathrm{PF}_{5}$ and especially $\mathrm{AsF}_{5}$ Lewis acids and the $\mathrm{EC}$ and $\mathrm{H}_{2} \mathrm{O}$ Lewis bases, whereas $\mathrm{POF}_{3}$ does not exhibit these Lewis acid-base interactions with either the EC electrolyte or $\mathrm{H}_{2} \mathrm{O}$. Rather, geometry optimization of the contact reactant complex between $\mathrm{POF}_{3}$ and $\mathrm{H}_{2} \mathrm{O}$ drifts apart towards separated, solvated species. Additionally, we predict the $\mathrm{P}-\mathrm{F}$ bond in $\mathrm{POF}_{3}$ is stronger than the $\mathrm{P}-\mathrm{F}$ bond in $\mathrm{PF}_{5}$ and significantly stronger than the As-F bond in $\mathrm{AsF}_{5}$. This suggests a greater energetic penalty to form $\mathrm{HF}$ from $\mathrm{POF}_{3}$, and a significantly lower barrier to form $\mathrm{HF}$ from $\mathrm{AsF}$. This is consistent with our calculations that predict a high barrier for HF generation from $\mathrm{POF}_{3}$ of $157.7 \mathrm{~kJ} \mathrm{~mol}^{-1}$, and suggests that $\mathrm{LiPOF}_{4}$ is a viable alternative to the state-of-the-art electrolyte additive, $\mathrm{LiPF}_{6}$. On the other hand, the first ligand exchange reaction between $\mathrm{H}_{2} \mathrm{O}$ and $\mathrm{PF}_{5}$ has a barrier of $114.2 \mathrm{~kJ} \mathrm{~mol}^{-1}$, which is still low enough that it reacts to form HF, albeit relatively slowly. Furthermore, because the transition state for $\mathrm{POF}_{3}$ to react with $\mathrm{H}_{2} \mathrm{O}$ to form $\mathrm{POF}_{2} \mathrm{OH}$ involves a five-fold coordinated $\mathrm{P}$ center and thus an energy penalty to hybridize $\mathrm{P}$ from $\mathrm{sp}^{3}$ to $\mathrm{sp}^{3} \mathrm{~d}$, it involves a significantly higher barrier $\left(157.7 \mathrm{~kJ}^{\mathrm{mol}}{ }^{-1}\right)$ to $\mathrm{HF}$ generation than the $114.2 \mathrm{~kJ} \mathrm{~mol}^{-1}$ barrier to generate $\mathrm{HF}$ from $\mathrm{PF}_{5}$. As a result of the $43.5 \mathrm{~kJ} \mathrm{~mol}^{-1}$ higher activation barrier, we predict a reduction in the Boltzmann factor of the rate constant by $\sim 10^{-8}$ for $\mathrm{HF}$ generation at $310 \mathrm{~K}$ from $\mathrm{POF}_{3}$ relative to $\mathrm{PF}_{5}$.

We predict that $\mathrm{AsF}_{5}$ is a stronger Lewis acid than either $\mathrm{PF}_{5}$ or $\mathrm{POF}_{3}$, and that formation the $\mathrm{AsF}_{5} \cdot \mathrm{H}_{2} \mathrm{O}$ dative complex is exothermic by $81.2 \mathrm{~kJ} \mathrm{~mol}^{-1}$. This complex then reacts to form HF with an activation barrier of $30.5 \mathrm{~kJ}^{\mathrm{mol}}{ }^{-1}$, relative to the $\mathrm{AsF}_{5} \cdot \mathrm{EC}$ reactant complex, suggesting that $\mathrm{LIB}$ electrolytes containing $\mathrm{LiAsF}_{6}$ will suffer capacity fading and a shortened service due to relatively facile HF generation in the electrolyte.

These results explain the mechanisms by which the $\mathrm{LiPF}_{6}, \mathrm{LiAsF}_{6}$ and $\mathrm{LiPOF}_{4}$ salt additives decompose in carbonate electrolytes. Our results predict that $\mathrm{PF}_{5}$, formed by decomposition of $\mathrm{LiPF}_{6}$ in typical $\mathrm{LIB}$ electrolytes, will react with $\mathrm{H}_{2} \mathrm{O}$ to produce $\mathrm{HF}$, which degrades transition metal oxide cathodes. However, we find that the barriers for the reaction of $\mathrm{POF}_{3}$ with $\mathrm{H}_{2} \mathrm{O}$ are relatively high leading to significantly slower generation of HF. Consequently, based on its stability with respect to generating $\mathrm{HF}$, we suggest that $\mathrm{LiPOF}_{4}$ should be investigated further as a potential electrolyte salt for LIBs to mitigate HF formation in liquid carbonate based electrolytes. However, its implementation will ultimately depend on whether it performs adequately in terms of $\mathrm{Li}^{+}$ conductivity and SEI formation. 


\section{AUTHOR INFORMATION}

\section{Corresponding Author}

*Charles B. Musgrave (charles.musgrave@ colorado.edu)

\section{ACKNOWLEDGMENTS}

This work was supported in part by NSF grant CHE-1214131 (CBM). We also gratefully acknowledge use of XSEDE supercomputing resources (NSF ACI-1053575) and the Janus supercomputer, which is supported by NSF grant CNS-0821794 and the University of Colorado Boulder. We also thank Dr. Aaron Holder and Chern-Hooi Lim for useful discussions.

\section{REFERENCES}

[1] D. Aurbach, Y. Talyosef, B. Markovsky, E. Markevich, E. Zinigrad, L. Asraf, J.S. Gnanaraj, H.J. Kim, in:, Electrochim. Acta, 2004, pp. 247-254.

[2] D. Aurbach, B. Markovsky, G. Salitra, E. Markevich, Y. Talyossef, M. Koltypin, L. Nazar, B. Ellis, D. Kovacheva, J. Power Sources 165 (2007) 491.

[3] Z. Chen, L.Z. Zhang, R. West, K. Amine, Electrochim. Acta 53 (2008) 3262.

[4] V. Borgel, E. Markevich, D. Aurbach, G. Semrau, M. Schmidt, J. Power Sources 189 (2009) 331.

[5] V. Etacheri, R. Marom, R. Elazari, G. Salitra, D. Aurbach, Energy Environ. Sci. 4 (2011) 3243.

[6] L. Yang, T. Markmaitree, B.L. Lucht, J. Power Sources 196 (2011) 2251.

[7] J.B. Goodenough, Y. Kim, Chem. Mater. 22 (2010) 587.

[8] D. Aurbach, B. Markovsky, A. Rodkin, M. Cojocaru, E. Levi, H.J. Kim, Electrochim. Acta 47 (2002) 1899.

[9] H. Yang, G. V. Zhuang, P.N. Ross, J. Power Sources 161 (2006) 573.

[10] T. Kawamura, S. Okada, J. ichi Yamaki, J. Power Sources 156 (2006) 547.

[11] K. Tasaki, S. Nakamura, J. Electrochem. Soc. 148 (2001) A984.

[12] K. Tasaki, K. Kanda, S. Nakamura, M. Ue, J. Electrochem. Soc. 150 (2003) A1628.

[13] S.F. Lux, I.T. Lucas, E. Pollak, S. Passerini, M. Winter, R. Kostecki, Electrochem. Commun. 14 (2012) 47.

[14] J.B. Goodenough, Y. Kim, Chem. Mater. 22 (2010) 587.

[15] R. Dedryvère, H. Martinez, S. Leroy, D. Lemordant, F. Bonhomme, P. Biensan, D. Gonbeau, J. Power Sources 174 (2007) 462. 
[16] Y. Okamoto, J. Electrochem. Soc. 160 (2013) A404.

[17] S.F. Lux, J. Chevalier, I.T. Lucas, R. Kostecki, ECS Electrochem. Lett. 2 (2013) A121.

[18] B. Markovsky, J. Power Sources 119-121 (2003) 504.

[19] R. Yazami, Y. Ozawa, H. Gabrisch, B. Fultz, Electrochim. Acta 50 (2004) 385.

[20] L. Dahéron, R. Dedryvère, H. Martinez, M. Ménétrier, C. Denage, C. Delmas, D. Gonbeau, Chem. Mater. 20 (2008) 583.

[21] Y. Zhao, D.G. Truhlar, Theor. Chem. Acc. 120 (2007) 215.

[22] P.C. Hariharan, J.A. Pople, Theor. Chim. Acta 28 (1973) 213.

[23] V. a. Rassolov, M. a. Ratner, J. a. Pople, P.C. Redfern, L. a. Curtiss, J. Comput. Chem. 22 (2001) 976.

[24] M.M. Francl, J. Chem. Phys. 77 (1982) 3654.

[25] M.S. Gordon, M.W. Schmidt, in:, Theory Appl. Comput. Chem., 2005, pp. 1167-1189.

[26] M.W. Schmidt, K.K. Baldridge, J.A. Boatz, S.T. Elbert, M.S. Gordon, J.H. Jensen, S. Koseki, N. Matsunaga, K.A. Nguyen, S. Su, T.L. Windus, M. Dupuis, J.A. Montgomery, J. Comput. Chem. 14 (1993) 1347.

[27] A. Karton, S. Parthiban, J.M.L. Martin, J. Phys. Chem. A 113 (2009) 4802.

[28] M. Cossi, V. Barone, J. Chem. Phys. 109 (1998) 6246.

[29] M.A. Spackman, J. Comput. Chem. 17 (1996) 1.

[30] Y. Chernyak, J. Chem. Eng. Data 51 (2006) 416.

[31] R. Dedryvère, H. Martinez, S. Leroy, D. Lemordant, F. Bonhomme, P. Biensan, D. Gonbeau, J. Power Sources 174 (2007) 462.

[32] D. Aurbach, B. Markovsky, G. Salitra, E. Markevich, Y. Talyossef, M. Koltypin, L. Nazar, B. Ellis, D. Kovacheva, J. Power Sources 165 (2007) 491.

[33] D.J. Grant, M.H. Matus, J.R. Switzer, D.A. Dixon, J.S. Francisco, K.O. Christe, J. Phys. Chem. A 112 (2008) 3145.

[34] J.S. Gnanaraj, V.G. Pol, A. Gedanken, D. Aurbach, Electrochem. Commun. 5 (2003) 940.

[35] Kikuyama, H., Fukudome, T., Waki, M., \& Yazaki, H. (2003). U.S. Patent No. 6,514,474. Washington, DC: U.S. Patent and Trademark Office.CA2332357A1, n.d. 
Table 1 : The Effect of Solvent Model on the

Energetics of HF Generation by Reaction 2

\begin{tabular}{|c|c|c|}
\hline $\begin{array}{c}\text { Species and Solvent } \\
\text { Model }\end{array}$ & $\begin{array}{c}\text { Activation } \\
\text { Barrier } \\
\left(\mathrm{kJ} \mathrm{mol}^{-1}\right)\end{array}$ & $\begin{array}{l}\text { Reaction } \\
\text { Enthalpy } \\
\left(\mathrm{kJ} \mathrm{mol}^{-1}\right)\end{array}$ \\
\hline $\mathrm{PF}_{5}-$ Implicit & 131.4 & 39.7 \\
\hline $\mathrm{PF}_{5}-1 \mathrm{EC}+\mathrm{PCM}$ & 114.2 & 14.6 \\
\hline $\mathrm{PF}_{5}-2 \mathrm{EC}+\mathrm{PCM}$ & 115.5 & 12.6 \\
\hline $\mathrm{PF}_{5}-3 \mathrm{EC}+\mathrm{PCM}$ & 115.9 & 11.3 \\
\hline $\mathrm{POF}_{3}-$ Implicit & 151.5 & -15.1 \\
\hline $\mathrm{POF}_{3}-1 \mathrm{EC}+\mathrm{PCM}$ & 157.7 & -3.8 \\
\hline $\mathrm{POF}_{3}-2 \mathrm{EC}+\mathrm{PCM}$ & 148.5 & -10.5 \\
\hline $\mathrm{POF}_{3}-3 \mathrm{EC}+\mathrm{PCM}$ & 145.2 & -9.2 \\
\hline $\mathrm{AsF}_{5}-$ Implicit & 68.6 & 39.7 \\
\hline $\mathrm{AsF}_{5}-1 \mathrm{EC}+\mathrm{PCM}$ & 30.5 & -11.3 \\
\hline $\mathrm{AsF}_{5}-2 \mathrm{EC}+\mathrm{PCM}$ & 33.9 & -12.6 \\
\hline $\mathrm{AsF}_{5}-3 \mathrm{EC}+\mathrm{PCM}$ & 31.8 & -13.4 \\
\hline
\end{tabular}

Table 2: Properties of $\mathrm{POF}_{3}, \mathrm{PF}_{5}$, and $\mathrm{AsF}_{5}$ and Their Lewis Acid-Base Complexes with $\mathrm{H}_{2} \mathrm{O}$

$\begin{array}{lll}\text { P or As } & & \\ & \text { CUMO Energy Relative } & \text { Complexation }\end{array}$

Species

Charge to $\mathrm{H}_{2} \mathrm{O} \mathrm{HOMO}$

$\left.(\mathrm{kJ} \mathrm{mol})^{-1}\right)$

Distance in Complex (

Energy

$\left(\mathrm{kJ} \mathrm{mol}{ }^{-1}\right)$

\begin{tabular}{ccccc}
\hline $\mathrm{POF}_{3}$ & 1.19 & 1255.2 & 2.98 & 6.7 \\
$\mathrm{PF}_{5}$ & 1.31 & 1153.1 & 1.92 & -41.8 \\
$\mathrm{AsF}_{5}$ & 1.40 & 1097.5 & 1.99 & -81.2
\end{tabular}




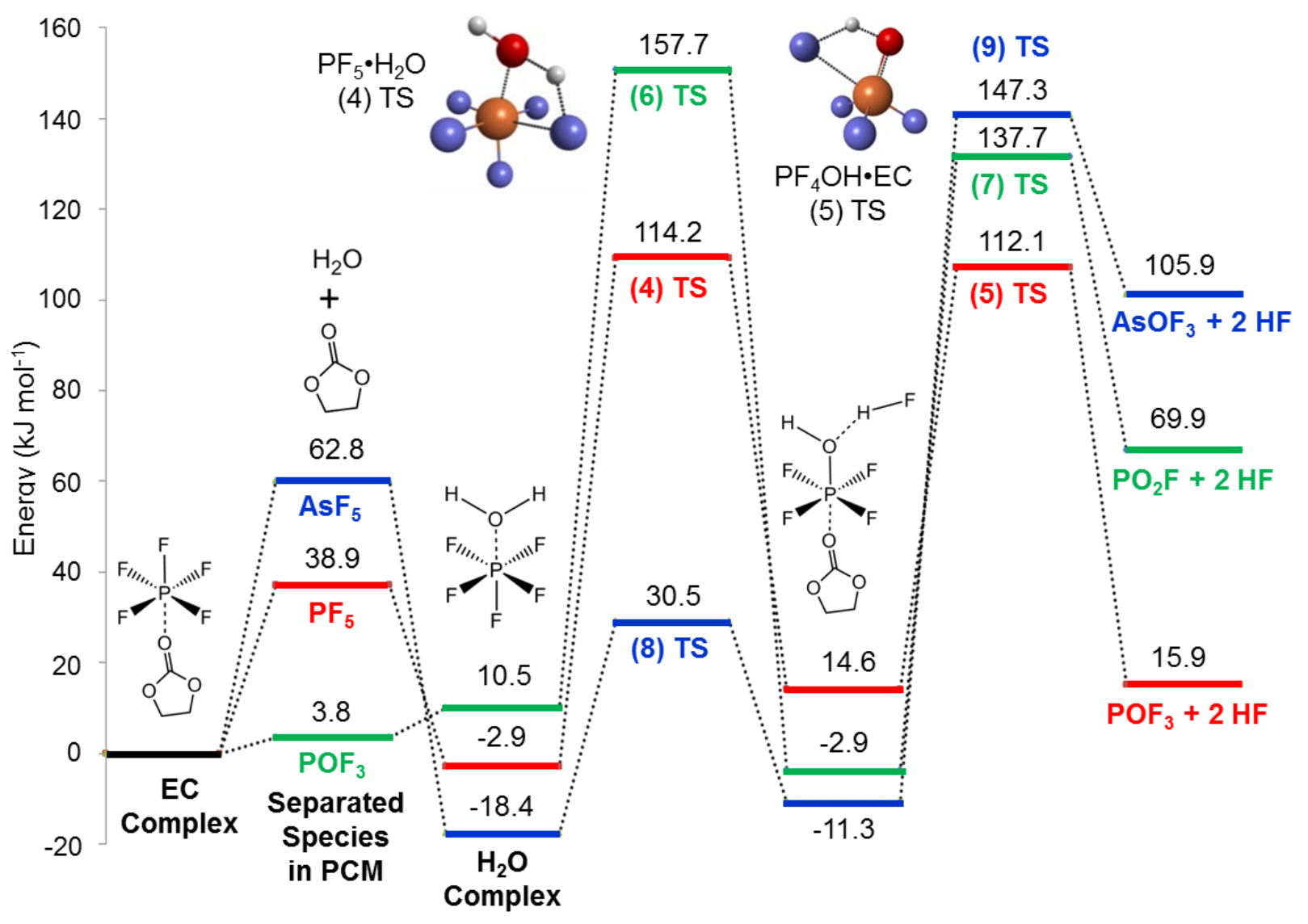

Figure 1. Schematic potential energy surfaces for reactions between $\mathrm{H}_{2} \mathrm{O}$ and $\mathrm{PF}_{5}$ (red), $\mathrm{POF}_{3}$ (green), and $\mathrm{AsF}_{5}$ (blue) that form $\mathrm{HF}$ are illustrated. The initial (reference) states are the electrolyte constituent $\left(\mathrm{PF}_{5}, \mathrm{POF}_{3}\right.$, and $\mathrm{AsF}_{5}$ ) complexed with an EC solvent molecule and a separated $\mathrm{H}_{2} \mathrm{O}$ with all species solvated in EC electrolyte modeled by the PCM continuum solvent model. Next, each complex dissociates to form $\mathrm{PF}_{5}, \mathrm{POF}_{3}$, and $\mathrm{AsF}_{5}$, and separated EC and $\mathrm{H}_{2} \mathrm{O}$. This state provides an estimate of the energy barrier for $\mathrm{H}_{2} \mathrm{O}$ to displace $\mathrm{EC}$ to complex with each species. The next stationary state shows the complexes with $\mathrm{H}_{2} \mathrm{O}$, which have similar stabilities to the complexes with EC, although the much higher EC concentration makes these states less favorable. Although $\mathrm{PF}_{5}$ and $\mathrm{AsF}_{5}$ are predicted to form Lewis Acid-Base complexes with both $\mathrm{EC}$ and $\mathrm{H}_{2} \mathrm{O}, \mathrm{POF}_{3}$ is not predicted to form stable complexes to either. From the complexes with $\mathrm{H}_{2} \mathrm{O}$, each species proceeds through a TS for the ligand exchange Reactions (4), (6), and (8) that produce $\mathrm{PF}_{4} \mathrm{OH} \cdot \mathrm{EC}-\mathrm{HF}, \mathrm{POF}_{2} \mathrm{OH} \cdot \mathrm{EC}-\mathrm{HF}$, and $\mathrm{AsF}_{4} \mathrm{OH} \cdot \mathrm{EC}-\mathrm{HF}$ where each ligand exchange product is complexed to EC and hydrogen bonded to HF. Only the TS structure of Reaction (4) is shown. See SI Figure S2 for the TS structures of Reactions (6) and (8). Note that only a figure for $\mathrm{PF}_{4} \mathrm{OH} \cdot \mathrm{EC}-\mathrm{HF}$, the product of Reaction (4), is shown. Next, the reactions proceed through a second TS for Reactions (5), (7), and (9) to form a second $\mathrm{HF}$ and $\mathrm{POF}_{3}, \mathrm{PO}_{2} \mathrm{~F}$, and $\mathrm{AsOF}_{3}$.

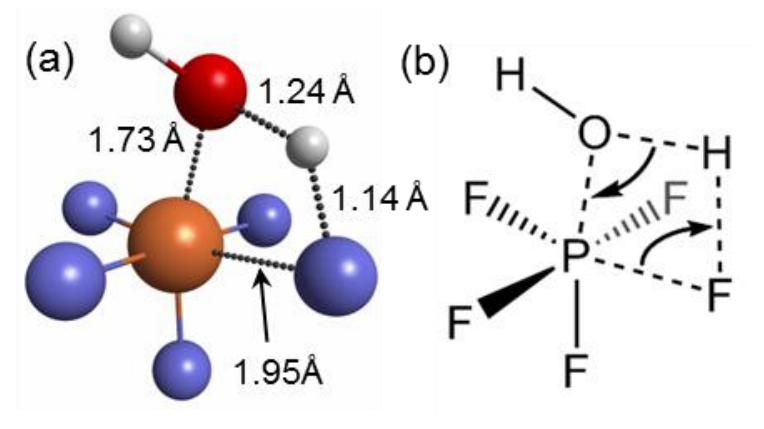

Figure 2. (a) The structure of the TS of Reaction (4) in PCM with a solvating EC (not shown) is illustrated. This ligand exchange reaction produces $\mathrm{HF}$ and involves a barrier $114.2 \mathrm{~kJ} \mathrm{~mol}^{-1}$ and a reaction enthalpy is $14.6 \mathrm{~kJ}$ $\mathrm{mol}^{-1}$, referenced to the $\mathrm{PF}_{5} \cdot \mathrm{EC}$ complex. The red, white, purple and orange atoms are $\mathrm{O}, \mathrm{H}, \mathrm{F}$ and $\mathrm{P}$. (b) A18 
schematic illustration of Reaction (4) showing the ligand exchange reaction involving the simultaneous dissociation of the P-F and $\mathrm{O}-\mathrm{H}$ bonds and formation of the $\mathrm{P}-\mathrm{O}$ and $\mathrm{HF}$ bonds.

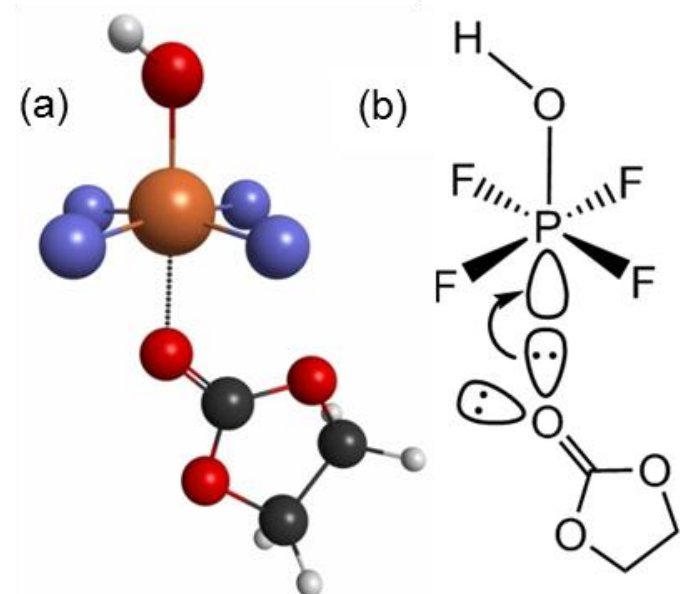

Figure 3. (a) The $\mathrm{PF}_{4} \mathrm{OH} \cdot \mathrm{EC}$ product of Reaction (4), (the HF product is not shown). The red, white, purple, orange and black atoms represent $\mathrm{O}, \mathrm{H}, \mathrm{F}, \mathrm{P}$ and $\mathrm{C}$. (b) Illustration showing the Lewis acid-base complex between $\mathrm{PF}_{4} \mathrm{OH}$ and $\mathrm{EC}$, which returns the $\mathrm{P}$ atom to an octahedral-like coordination.
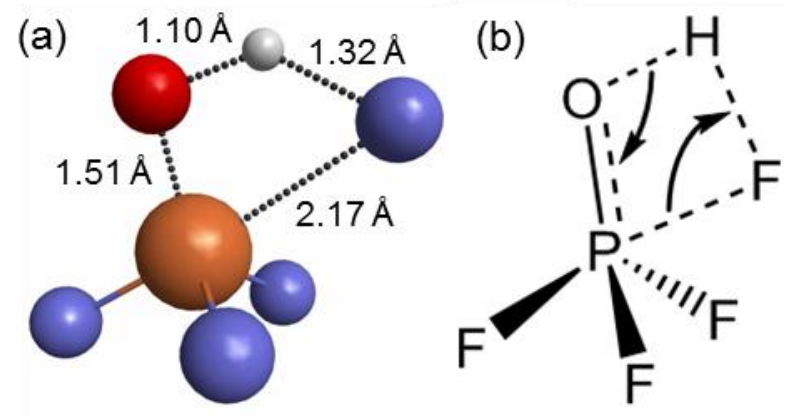

Figure 4. The (a) transition state of Reaction (5) (the spectating EC molecules is not shown). The red, white, purple and orange atoms represent $\mathrm{O}, \mathrm{H}, \mathrm{F}$ and $\mathrm{P}$. (b) Illustration of the ligand exchange reaction that forms $\mathrm{HF}$. As the reaction approaches the TS, $\mathrm{PF}_{4} \mathrm{OH} \cdot \mathrm{EC}$ dissociates, while at the TS the P-F and O-H bonds dissociates as the H-F and $\mathrm{P}=\mathrm{O} \pi$-bond forms. Reaction (5) has an activation energy of $97.5 \mathrm{~kJ} \mathrm{~mol}^{-1}$ and reaction enthalpy of $17.6 \mathrm{~kJ} \mathrm{~mol}^{-}$ ${ }^{1}$, referenced to the $\mathrm{PF}_{4} \mathrm{OH} \cdot \mathrm{EC}$ reactant complex.
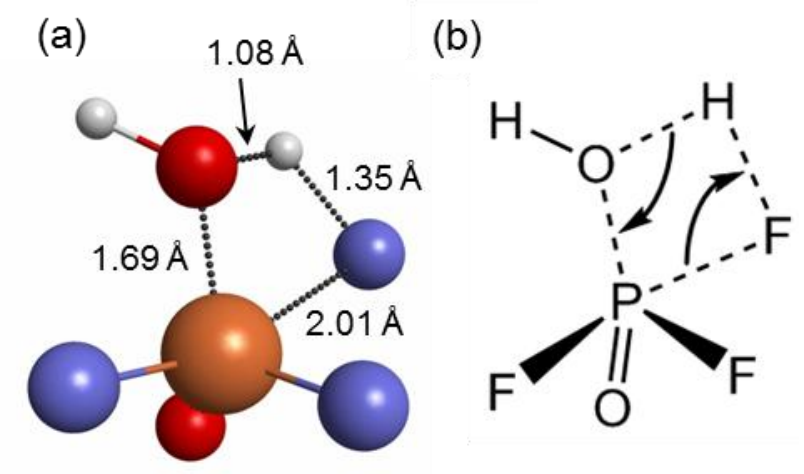

Figure 5. (a) Structure of the TS of Reaction (6) is shown where $\mathrm{H}_{2} \mathrm{O}$ reacts with $\mathrm{POF}_{3}$ through ligand exchange to form $\mathrm{HF}$ and $\mathrm{POF}_{2} \mathrm{OH}$. The red, white, purple, orange and black atoms represent $\mathrm{O}, \mathrm{H}, \mathrm{F}, \mathrm{P}$ and $\mathrm{C}$. (b) Schematic illustration of the ligand exchange reaction where the H-F and P-O bonds form as the P-F and $\mathrm{OH}$ bonds dissociate. Reaction (6) has an activation energy of $157.7 \mathrm{~kJ} \mathrm{~mol}^{-1}$ and is exothermic by $3.8 \mathrm{~kJ} \mathrm{~mol}^{-1}$, referenced to the solvated reactants. 


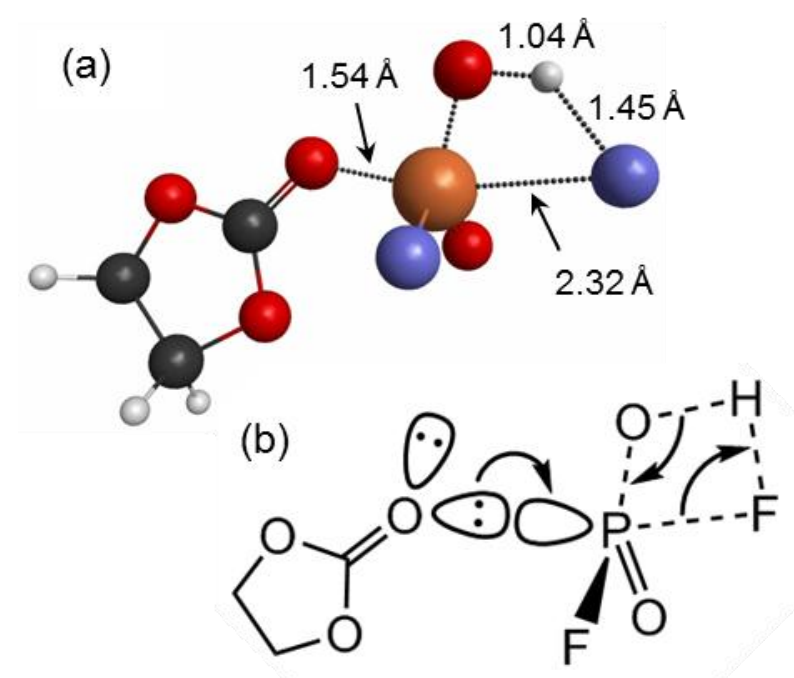

Figure 6. (a) The structure of the TS for Reaction (7) is shown where the red, white, purple, orange and black atoms represent $\mathrm{O}, \mathrm{H}, \mathrm{F}, \mathrm{P}$ and $\mathrm{C}$. (b) A schematic illustration of the $\mathrm{HF}$ formation reaction involving dissociation of the P-F and O-H bonds and simultaneous formation of the H-F and P-O bonds. Reaction (7) is predicted to occur with an activation energy of $141.4 \mathrm{~kJ} \mathrm{~mol}^{-1}$ and reaction energy of $73.6 \mathrm{~kJ} \mathrm{~mol}^{-1}$, referenced to the $\mathrm{PF}_{2} \mathrm{OOH} \cdot \mathrm{EC}$ complex. 